\title{
VIOLÊNCIA CONTRA A MULHER: UMA PROBLEMÁTICA DE SAÚDE PÚBLICA
}

\author{
Diego Teodoro Venâncio Lopes \\ Matheus Reis de Oliveira \\ Tacianne Hott de Souza \\ Samantha Peixoto Pereira ${ }^{1}$
}

RESUMO: O presente trabalho tem por objetivo analisar frente aos fatores decorrentes da violência contra a mulher analisados na literatura, com foco nas vertentes quanto a violência contra a mulher que mesmo em plena atualidade ainda ocorre e é necessário que possamos entender como os atendimentos vinculados à saúde pública podem ser essenciais nestes casos. A metodologia utilizada foi uma revisão de literatura a partir das análises de trabalhos publicados nas seguintes bases de dados: Scielo, Google Acadêmico, BVS e Lilacs, entre os anos de 1990 a 202I. Tendo como fator resultante das pesquisas os aspectos socioeconômicos e psicossociais que interferem nos aspectos de violência contra a mulher que ainda são frequentes na população, mesmo com o índice de enfrentamento ao isolamento social da pandemia da covid-ı. Destaca-se a importância de enfatizar a busca por melhorias nas estratégias dos vários segmentos a fim de minimizar os danos resultantes da violência contra a mulher e que podem ser minimizados de acordo com estratégias de saúde no cenário brasileiro.

Palavras-chave: Violência contra a Mulher. Atenção à Saúde. Isolamento social. Covid-ı9.

ABSTRACT: This study aims to analyze the factors resulting from violence against women analyzed in the literature, focusing on the aspects of violence against women that even today still occurs and it is necessary that we understand how the services related to public health may be essential in these cases. The methodology used was a literature review based on the analysis of works published in the following databases: Scielo, Google Academic, BVS and Lilacs, between 1990 and 2021. The socioeconomic and psychosocial aspects that resulted from the research were used as a factor. interfere with aspects of violence against women that are still frequent in the population, even with the index of coping with the social isolation of the pandemic of covid-ig.

Keywords: Violence against Women. Health Care. Social Isolation. Covid-I9.

\footnotetext{
${ }^{1}$ Cirurgiã Dentista graduada pela Universidade de Odontologia da USS-Universidade Severino Sombra, Vassouras/RJ-(2016). Especialista em Odontologia Legal pela FG, Porto Alegre/RS (2020).Doutora em Ciências Odontológicas - Área de Concentração em Clínicas Odontológicas: ênfase em Periodontia(2020). Mestre em Ciências da Educação pela UNIVERSIDADE DEL NORTE, ASSUNÇÃO-(2009). E-mail: samanthapeixoto84@gmail.com
} 


\section{INTRODUÇÃO}

Para Marcondes Filho (200I) a palavra violência vem tanto do latim violentia, que significa abuso de força, como de violare, no sentido de transgredir o respeito devido a uma pessoa. Para Aristóteles, a violência é tudo aquilo que vem do exterior e se opõe a tudo aquilo de interior que é natural, onde alguém é obrigado a fazer aquilo que não deseja( uma imposição física que é externa contra uma interioridade absoluta e uma vontade livre).

O que muitos não sabem é que a violência e seus desdobramentos estão inseridos no conceito ampliado de saúde pública, pois tudo o que representa um agravo ou ameaça à vida está incluído nesse universo da saúde.

Segundo a Organização Mundial de Saúde (OMS), a violência é definida como "uso intencional de força física ou do poder, real ou em ameaça contra si próprio, contra outra pessoa, contra um grupo ou comunidade, que resulte ou tenha possibilidade de resultar em lesão, morte, dano psicológico, deficiência de desenvolvimento ou privação de liberdade", e é um problema em constante crescimento que vem se tornando foco de discussão na saúde coletiva.

Levando em consideração um problema de saúde pública, as agressões físicas podem acarretar alguns agravos com relação a condições patológicas, incluindo as mortes por homicídios, suicídios ou ideação suicida, além de infecções sexualmente transmissíveis. Independente de idade, raça, credo, sexo, cultura e classe social, a violência física e/ou psicológica, atinge a maior parcela da população mundial, sendo a variante apenas em seu grau e proporção entre homens e mulheres. Algumas agressões são acometidas em locais públicos e praticadas por pessoas do mesmo sexo, já as agressões contra as mulheres ocorrem predominantemente dentro de sua própria residência e realizadas por agressores do sexo masculino com um histórico íntimo com a vítima (Santiago et al.,2014).

Estudos internacionais mostram altas prevalências de problemas nos serviços de saúde. Uma pesquisa em atenção primária apresentou uma frequência de $21,4 \%$ das mulheres relatando violência doméstica a partir dos 18 anos. Assim, é perceptível que os serviços básicos de saúde são importantes na deteç̧ão do problema, pois possui uma grande cobertura e contato com as mulheres, reconhecendo e acolhendo o caso antes de incidentes mais graves (Schraiber et al.,2002) 
É válido ainda ressaltar que essas violências traduzem-se em inúmeras repercussões para a saúde das mulheres e em sua qualidade de vida. A violência conjugal e o estupro têm sido relacionado a maiores índices de suicídios, abusos de drogas e álcool, queixas vagas, cefaléia, distúrbios gastrointestinais e sofrimentos psíquicos em geral. Para tanto, o objetivo deste trabalho é relatar as vertentes quanto a violência contra a mulher que mesmo em plena atualidade ainda ocorre e é necessário que possamos entender como os atendimentos vinculados à saúde pública podem ser essenciais nestes casos.

\section{METODOLOGIA}

O presente estudo, trata-se de uma revisão de literatura, com o objetivo de proporcionar o devido conhecimento sobre a violência contra a mulher no âmbito da saúde pública, em especial na atenção primária, bem como seus desdobramentos enquanto fator proporcionador de diminuição de qualidade de vida. Baseando-se como descritores das palavras chaves nos Descritores em Ciência da Saúde (DECs): Violência contra a Mulher, Atenção à Saúde, Isolamento social, Covid-ı. A base literária que fundamenta este trabalho foi criteriosamente selecionada de acordo com o foco de abordagem do estudo presentes nos seguintes bancos de dados, Scielo, Google Acadêmico, BVS e Lilacs, entre os anos de 1990 a 2021.

\section{RESULTADOS E DISCUSSÃO}

Para entendermos melhor a violência como uma questão da saúde pública brasileira, precisamos entender alguns aspectos históricos: A partir da década de 1980, a problemática da violência adquiriu maior força nos debates políticos e sociais e principalmente no planejamento em saúde pública. Nesse período que a Organização Mundial da Saúde (OMS) e Organização Panamericana de Saúde (OPAS) começaram a falar explicitamente em violência. Em tempos passados se fazia uso da rubrica "causas externas” da Classificação Internacional de Doenças, onde se incluía atos como suicídios, homicídios e acidentes fatais. Em 1994, a Organização Panamericana de Saúde realizou uma conferência internacional com os Ministros de Saúde das Américas, pesquisadores e especialistas sobre o tema. 
Assim, foi destacado a constatação de que a violência, devido ao grande número de vítimas e à magnitude de suas sequelas físicas e psicológicas, adquire um caráter endêmico e se tornou uma responsabilidade da Saúde Pública, uma vez que cabe ao setor o atendimento de urgência, tratar e reabilitar as vítimas (Minayo,2006).Em seguida, a Organização Mundial da Saúde começou a desenvolver bem como estimular pesquisas internacionais sobre a temática da violência e seus desdobramentos (OMS,2002).

Dessa forma, constatou-se que a violência praticada contra as mulheres é um fenômeno universal que ocorre em todo o mundo, sendo, frequentemente, seus perpetuadores pessoas bem conhecidas pelas vítimas (Feres Junior 2005). Em 1997, a Organização Mundial da Saúde caracterizou a violência da seguinte forma (Krugg,2002, p.6, tradução nossa):

I- Violência autodirigida: dividida entre comportamento suicida e auto-agressão;

2- Violência interpessoal: correspondendo à violência familiar, entre parceiros e comunitários (a familiar geralmente ocorrem no espaço de residência e última em espaços mais populares);

3- Violência coletiva: abrange as violências social, econômica e política.

Dessa forma torna-se necessário que os profissionais da saúde como, Médicos, Cirurgiões-Dentistas, Fisioterapeutas, Enfermeiros, Nutricionistas, Psicólogos, Educadores físicos, tenham o devido conhecimento e assim possuírem sensibilidade para conseguirem lidar com todas as demandas dos seus pacientes, incluindo a identificação de uma possível violência doméstica, fator que definido como qualidade de atendimento.

Para o Ministério da Saúde, a definição de qualidade é:

Grau de atendimento a padrões estabelecidos, frente às normas e protocolos que organizam as ações e práticas assim como aos conhecimentos técnicos científicos atuais (Ministério da Saúde, 1990).

Frente ao exposto, é evidente que o reconhecimento e a prevenção da violência não são conteúdos simples, assim o setor da saúde carece de preparo e regularidade, já que a prevenção da violência exige grandes esforços como, superar as noções de "fatalidade" e "inventário" próprio do senso comum (Genebra et al.,2008).Outro fator relevante a ser citado, é que diante do atual cenário da pandemia do Covid-ı9, as questões de violência 
contra a mulher, continuam perpetuando mesmo com o distanciamento social decorrente das mudanças de hábitos da população advindos do isolamento social, que foi uma proposta da OMS propôs para que cada país no papel das autoridades nacionais implementarem mudanças de hábitos nas populações, o que tornou-se essencial com a finalidade de minimizar a contaminação e disseminação do vírus na população. Medidas bruscas foram necessárias para que não assolaram os serviços de atendimento à saúde em consonância ao cenário da pandemia do Covid-ı9, no entanto o crescente número de casos de violência contra a mulher ainda tem afetado significativamente a vida de muitas famílias (Souza, 2021).

Ainda assim, a utilização dos serviços de saúde diante deste cenário da pandemia da Covid-ı foi agravando com a elevada frequência das vítimas deste vírus mas ainda assim estudos apontaram que alguns países tiveram um considerável aumento no que destaca as vítimas de violência doméstica, e são acometidas com aspectos de desenvolver mais problemas de saúde, resultados dos maus tratos e ainda da violência que acarreta danos à saúde e consequentemente chega a um ponto que a frequência na procura por atendimentos nos serviços de saúde de urgências e emergências aumentam (Ministério da Mulher,2020).

É notória a importância da sociedade mesmo em tempos de pandemia da Covid-ı9, assegurar as informações de apoio e incentivo quanto a denunciar os hábitos de agressão e violência contra mulheres, fazendo com que as vítimas sejam acolhidas diante da sociedade e que não sejam discriminadas ou ainda sintam isoladas do convívio social. Não obstante, estratégias para aumentar o número de grupos de apoio e acolhimento frente as vítimas de violência , bem como serviços e capacitações para os profissionais da área de saúde no que diz respeito a área de saúde coletiva, podem incluir neste aspecto, o fortalecimento e amparo quanto a prevenção e ser uma tomada de decisões mais frequente no apoio ao funcionamento de abrigos para acolher as mulheres que infelizmente ainda são vitimadas (Santos, 2020; Vieira,2020).

Diante dos argumentos apresentados, fica evidente que os profissionais da saúde devem cada vez mais buscarem conhecimentos sobre essa temática abordada, já que ela apresenta inúmeros desdobramentos, os quais devem ser notados para que ações de 
melhorias possam ser traçadas e colocadas em práticas no âmbito social como também da saúde brasileira.

\section{CONSIDERAÇÕES FINAIS}

Conclui-se, portanto, que a violência contra a mulher é uma banalidade já enfatizada no legado histórico do Brasil, e assim sua resolução é mais complexa, já que requer um trabalho em conjunto de vários segmentos, com um destaque para estratégias de saúde no cenário brasileiro. O presente trabalho, buscou demonstrar a relevância desse tema para os profissionais de saúde como também o incentivo de busca de conhecimentos sobre esse assunto proporcionando-os mais sensibilidade para conseguirem identificar e lidar com essa questão.

Os atendimentos realizados na Estratégia Saúde da Família (ESF), são de suma importância para a identificação dessa problemática, já que se trata do primeiro contato com o paciente e suas especificidades.

\section{REFERÊNCIAS BIBLIOGRÁFICAS}

FERES JÚNIOR, João. De Cambridge para o mundo, historicamente: revendo a contribuição metodológica de Quentin Skinner. Dados, v. 48, p. 655-679, 2005.

GEBARA, Carla Ferreira de Paula; LOURENÇO, Lélio Moura. Crenças de profissionais da saúde sobre violência doméstica contra crianças e adolescentes. Psicologia em Pesquisa, v. 2, n. I, p. 27-39, 2008.

KRUG, Etienne G. et al. The world report on violence and health. The lancet, v. 36o, n. 9339, p. 1083-1088, 2002.

MARCONDES FILHO, Ciro. Violência fundadora e violência reativa na cultura brasileira. São Paulo em perspectiva, v. I5, p. 20-27, 2001.

MINAYO, Maria Cecília de Souza. A inclusão da violência na agenda da saúde: trajetória histórica. Ciência \& Saúde Coletiva, v. II, p. 1259-1267, 2006.

Ministério da Mulher, e da família e direito humano [acesso is de out 2020] Disponível em: https://ouvidoria.mdh.gov.br/portal/indicadores>

Ministério da Saúde (BR). Departamento Nacional de Auditoria do SUS.Brasília (DF).1990. 
ORGANIZAÇÃO MUNDIAL DA SAÚDE; KRUG, Etienne G. Relatório mundial sobre violência e saúde. Genebra: Organização Mundial da Saúde, 2002.

SANTIAGO, Bianca Marques; DIAS, Isabella Jardelino. Violência de gênero contra a mulher: perfil de registros periciais da Gerência Executiva de Medicina e Odontologia Legal (GEMOL) João Pessoa/PB. Rev. bras. ciênc. saúde, p. 315-324, 2014.

Santos LSE, Nunes LMM, Rossi BA, Taets G. Impactos da pandemia de COVID-ig na violência contra a mulher: reflexões a partir da teoria da motivação humana de Abraham Maslow. Scielo preprints, 2020 [acesso is set 2020] Disponível em: DOI: https://doi.org/10.1590/SciELOPreprints.915

SCHRAIBER, Lilia Blima et al. Violência contra a mulher: estudo em uma unidade de atenção primária à saúde. Revista de Saúde Pública, v. 36, p. 470-477, 2002.

SOUSA, Ildenir Nascimento; SANTOS, Fernanda Campos dos; ANTONIETTI, Camila Cristine. Fatores desencadeantes da violência contra a mulher na pandemia COVID-I9: Revisão integrativa. Revista de Divulgação Científica Sena Aires, v. Io, n. I, p. 5I-60, 202I.

Vieira PR, Garcia LP, Maciel ELN. Isolamento social e o aumento da violência doméstica: o que isso nos revela? LILACS, 2020 [acesso em 26 de set 2020] Disponível em: https://doi.org/10.1590/1980-549720200033 